\title{
Loss of thalamic serotonin transporters in early drug-naïve Parkinson's disease patients is associated with tremor: an $\left[{ }^{123} I\right] \beta$-CIT SPECT study
}

\author{
V. Caretti · D. Stoffers $\cdot$ A. Winogrodzka $\cdot$ I.-U. Isaias • \\ G. Costantino $\cdot$ G. Pezzoli $\cdot$ C. Ferrarese $\cdot$ A. Antonini $\cdot$ \\ E.-Ch. Wolters · J. Booij
}

Received: 27 July 2007/ Accepted: 17 December 2007/Published online: 12 March 2008

(C) The Author(s) 2008

\begin{abstract}
In vitro studies revealed serotonin transporter (5-HTT) decline in Parkinson's disease (PD). Yet, few studies investigated thalamic 5-HTT in vivo and its effect on PD heterogeneity. We analyzed thalamic $\left[{ }^{123} \mathrm{I}\right] \beta$-CIT binding (mainly reflecting 5-HTT binding) in 32 drugnaïve PD patients and 13 controls with SPECT. Twenty-six patients were examined twice (17 months apart). Based on UPDRS scores, we identified subgroups of patients with moderate/severe tremor $\left(\mathrm{PD}_{\mathrm{T}}\right)$ and without tremor $\left(\mathrm{PD}_{\mathrm{WT}}\right)$ at the time of clinical diagnosis. Additionally, depressive symptoms were evaluated using the Beck Depression Inventory (BDI) at baseline. Mean thalamic specific to nonspecific $\left[{ }^{123} \mathrm{I}\right] \beta$-CIT binding ratio was lower in patients when compared to controls, and further decreased during follow-up. At baseline, average thalamic ratio was significantly lower in the $\mathrm{PD}_{\mathrm{T}}$ than in the $\mathrm{PD}_{\mathrm{WT}}$ subgroup. No correlation was found between BDI scores and thalamic binding ratios. Our findings show decline of $\left[{ }^{123} \mathrm{I}\right] \beta$-CIT
\end{abstract}

V. Caretti - D. Stoffers - A. Winogrodzka - E.-Ch. Wolters Department of Neurology, Vrije University Medical Center, Amsterdam, The Netherlands

V. Caretti · J. Booij

Department of Nuclear Medicine, Academic Medical Center, Amsterdam, The Netherlands

V. Caretti ( $\square)$ - I.-U. Isaias · G. Costantino · G. Pezzoli ·

A. Antonini

Parkinson Institute, Istituti Clinici di Perfezionamento,

Milan, Italy

e-mail: violacaretti@yahoo.it

I.-U. Isaias · G. Costantino · C. Ferrarese

Department of Neurology, University of Milan-Bicocca,

S. Gerardo Hospital, Monza, Italy binding to thalamic 5-HTT in PD and its possible contribution to tremor onset.

Keywords Parkinson's disease - Serotonin transporter · Thalamus · Tremor · Depression $\cdot\left[{ }^{123} \mathrm{I}\right] \beta$-CIT SPECT

\section{Introduction}

Degeneration of the dopaminergic system is still considered to be the pathological hallmark of Parkinson's disease (PD), although the serotonergic, cholinergic, noradrenergic and gamma-amino-butyric acid systems are affected as well (Hirsch et al. 2003). Importantly, when compared to the dopaminergic circuitry, these systems may actually be involved to a larger degree in the early stages of PD (Braak et al. 2003). Abnormalities in non-dopaminergic systems have now been implicated in the diversity of part of the motor and non-motor symptomatology in PD (Chaudhuri 2006; de Rijk et al. 1997; Henderson et al. 2000b). In particular, due to the widespread serotonergic innervations, serotonin (5-HT) may play a role in regulating other neurotransmitter activities (Fink et al. 2007). Post-mortem neurochemical studies in PD have detected up to a 50\% 5-HT loss in both the cortex and the basal ganglia brain regions (Birkmayer et al. 1985, 1987; Scatton et al. 1983). Moreover, neuronal loss and Lewy body formation not only affect the dopaminergic neurons (Forno 1996) but also the serotonergic system (Jellinger 1987). Whereas, loss of 5-HT in post-mortem PD studies is well established, its degeneration in vivo and particularly its potential role in affecting clinical PD presentation still awaits elucidation.

Various lines of evidence have suggested that 5-HT may be involved in the etiology of resting tremor in PD. Loss of striatal dopamine transporter (DAT) binding has been 
shown to correlate with rigidity/bradykinesia, but not with tremor (Spiegel et al. 2006) and, unlike rigidity and bradykinesia the response of resting tremor to levodopa therapy is variable at best (Koller et al. 1990). These findings would argue against a pure dopaminergic etiology of resting tremor. Since the late 1960s there has been continuous debate over the genesis of tremor. Lesion studies in animal models of parkinsonian tremor have mainly targeted midbrain and cerebellar areas (Wilms et al. 1999), thereby mainly lesioning ascending serotonergic projections to the forebrain. Tremor induced by harmaline in rats and chickens can be effectively antagonized by 5 HT supplementation (Bowman et al. 1968; Headley et al. 1976). It has been hypothesized that this tremorgenic compound may act indirectly by inhibiting the inhibitory serotonergic projections arising from the raphe nuclei (Headley et al. 1976). Finally, decrease in midbrain 5HT1a receptors in PD along with an association with resting tremor has been recently reported in a ${ }^{11} \mathrm{C}-\mathrm{WAY} 100635$ PET study (Doder et al. 2003).

Selective neurodegeneration within the thalamus may well contribute to the motor and non-motor symptoms of PD (Henderson et al. 2000a, b). Noteworthy is thalamic involvement in the extensive cerebral oscillatory network that is postulated to determine resting tremor in PD, as reported in various magnetoencephalografic studies (Schnitzler et al. 2006; Timmermann et al. 2003; Volkmann et al. 1996). Based on primate studies, experimental tremor generated by a thalamo-cortical mechanism has been defined as a Parkinson-like tremor, whereas, the olivo-cerebellar system was assessed to be responsible for the faster 'physiological' tremor (DeLong 1978; Lamarre et al. 1975). In the 1980s deep brain stimulation (DBS) was first applied to the thalamus in patients with severe tremor (Benabid et al. 1987). A multicenter European study reported thalamic DBS to be effective on PD tremor, while the other parkinsonian hallmarks did not receive consistent benefits (Limousin et al. 1999). Indeed, thalamic DBS is recommended for patients disabled only by tremor (Limousin-Dowsey et al. 1999).

5-HT may also play a crucial role in the pathogenesis of depression in PD. Several post-mortem studies as well as biochemical studies of breakdown products of 5-HT in the cerebral spinal fluid (CSF) have shown reduced 5-HT activity in the brain of PD patients (Birkmayer et al. 1987; Kostic et al. 1987; Kuhn et al. 1996; Scatton et al. 1983). Moreover, there is a functional polymorphism in the 5-HT transporter (5-HTT) synthesis, and the short allele (which synthesizes less 5-HTT) is associated with PD depression (Mossner et al. 2001). Clinically, treatment with selective 5-HT reuptake inhibitors (SSRI), e.g., citalopram, improves PD depressive symptoms (Antonini et al. 2006), although a role for dopaminergic drugs has also been suggested
(Barone et al. 2006). Interestingly, a $\left[{ }^{123} \mathrm{I}\right] \beta$-CIT SPECT study showed the capability of citalopram to block thalamic 5-HTT in depressed patients (Pirker et al. 1995), thus demonstrating the thalamus to be an anatomic site of action of an SSRI.

$\left[{ }^{123} \mathrm{I}\right] \beta$-CIT is cocaine derivate with high affinity for DAT (Boja et al. 1995) as well as for 5-HTT (Neumeyer et al. 1991). In vivo displacement studies in primates have shown striatal $\left[{ }^{123} \mathrm{I}\right] \beta$-CIT binding to be predominantly associated with DAT, whereas, binding in the diencephalon was mainly associated with 5-HTT (Innis et al. 1991; Laruelle et al. 1993). $\left[{ }^{123} \mathrm{I}\right] \beta$-CIT has been shown to be useful in monitoring the dopaminergic degeneration of the nigrostriatal pathway in PD (Innis 1994; Tissingh et al. 1998), but it may be also used to assess the integrity of thalamic 5-HTT (De Win et al. 2005).

In the light of these data we chose to investigate 5 -HTT binding in the thalamic area by means of $\left[{ }^{123} \mathrm{I}\right]$ $\beta$-CIT SPECT. The primary aim of this study was to assess whether in PD thalamic 5-HTT binding is decreased in vivo. Consequently, we investigated thalamic 5-HTT binding as well as striatal DAT binding in 32 unrelated drug-naïve early PD patients and in 13 healthy subjects using $\left[{ }^{123} \mathrm{I}\right] \beta$-CIT SPECT. Additionally, we hypothesized that 5-HTT binding declines as disease progresses. In order to verify this hypothesis we repeated scans on 26 patients in an average of 17 months later. Finally, we investigated whether 5-HTT loss affects PD phenotypic heterogeneity. We postulated that 5-HTT loss may be associated with the presence of tremor and depression at disease onset.

\section{Materials and methods}

\section{Subjects}

We studied 32 drug-naïve early-stage PD patients as well as 13 healthy volunteers. Diagnosis of PD was made according to UK Brain Bank criteria (Hughes et al. 1992). Patients were recruited regardless of their phenotype, i.e., presence of tremor or depression, as the primary aim of the study was to investigate whether 5-HTT binding has decreased in vivo in an early drug-naïve PD population. A $\left[{ }^{123} \mathrm{I}\right] \beta$-CIT follow-up scan was performed on 26 patients out of the initial group over a period (mean \pm SD) of $17 \pm 9$ months. At baseline, all patients were drug-naïve for dopaminergic treatment and two patients used benzodiazepines, whereas, at follow-up, they had initiated dopaminergic medication (levodopa or a $\mathrm{D}_{2}$ agonist).

PD patients with dementia were not included: a MiniMental State Examination (MMSE) score below 26 was used as an exclusion criterion. 
At baseline, PD severity was assessed using the motor part of the Unified Parkinson's Disease Rating Scale (UPDRS-III). Based on UPDRS tremor scores (total score on item 20), we categorized patients in two subgroups: PD patients with moderate/severe tremor at onset $\left(\mathrm{PD}_{\mathrm{T}}\right.$ subgroup; tremor score $\geq 2$ in at least one limb) and $\mathrm{PD}$ patients without tremor at onset $\left(\mathrm{PD}_{\mathrm{WT}}\right.$ subset; tremor score of 0 ). Note that all patients with tremor had a score equal to zero on item 21: they revealed resting but no action tremor during clinical examination. The two groups displayed no significant difference in rigidity and bradykinesia UPDRS scores (items 18, 19, 22, 27, 28, 29, 30 and 31$)$. In contrast, patients $(n=12)$ who had a UPDRS tremor score of 1 were not included in any of the subset.

At the time of the first scan, the Beck Depression Inventory scale (BDI) was used to assess depressive symptoms (Visser et al. 2006). See Table 1 for details on demographic and clinical data of the participants.

Patients were recruited at the VU University Medical Center (VUMC), Movement Disorders Clinic. The Hospital Ethics Committee approved the study and all patients signed informed consent forms.

\section{SPECT procedure}

SPECT studies were performed using a brain-dedicated system, the Strichmann Medical Equipment $810 \times$. The Strichmann camera system consists of 12 individual crystals, each equipped with a focusing collimator. The transaxial resolution is $7.6 \mathrm{~mm}$ full-width at half-maximum (FWHM) (Vermeulen et al. 1995). The energy window was set at 135-190 keV. Subjects received potassium iodine orally to block thyroid uptake of free radioactive iodine. $\left[{ }^{123} \mathrm{I}\right] \beta$-CIT (specific activity of $>185 \mathrm{MBq} / \mathrm{nmol}$; radiochemical purity $>99 \%$ ) was injected intravenously as a bolus, at a dose of approximately $110 \mathrm{MBq} .\left[{ }^{123} \mathrm{I}\right]$ labeling of $\beta$-CIT was performed as described earlier (Tissingh et al. 1998).

SPECT image acquisition was performed $24 \mathrm{~h}$ after injection, a time point at which $\left[{ }^{123} \mathrm{I}\right] \beta$-CIT binding to striatal DAT and thalamic 5-HTT is in an equilibrium state (Pirker et al. 2000). Slices were acquired during $300 \mathrm{~s}$ periods from the orbitomeatal line to the vertex with an interslice distance of $10 \mathrm{~mm}$. Data acquisition took place in a $128 \times 128$ matrix. Attenuation correction and reconstruction of the images were performed as described earlier (Booij et al. 1997a, b).

\section{Data processing}

Analysis of the $\left[{ }^{123} \mathrm{I}\right] \beta$-CIT binding was performed on two contiguous transverse slices representing the most intense striatal and thalamic binding. A standard region of interest (ROI) template was manually drawn with the aid of a stereotactic atlas. In order to distinguish the forebrain from the brainstem, we defined the striatal inferior level to be the anatomic limit between the midbrain and the thalamic region.

Specific striatal $\left[{ }^{123} \mathrm{I}\right] \beta$-CIT binding to DAT in whole striatum, putamen and caudate nucleus and specific thalamic $\left[{ }^{123} \mathrm{I}\right] \beta$-CIT binding to 5 -HTT were calculated using the formula:

$$
\begin{aligned}
& {[(\text { mean counts in specific ROI })} \\
& \quad-(\text { mean counts in non }- \text { specific ROI })] \\
& \quad /(\text { mean counts in non }- \text { specific } \mathrm{ROI})
\end{aligned}
$$

This formula is referred as the specific to non-specific $\left[{ }^{123} \mathrm{I}\right] \beta$-CIT binding ratio (SNS binding ratio). The occipital region was chosen as reference region because of negligible density for both DAT and 5-HTT (Laruelle et al. 1994a).
Table 1 Demographic and clinical data of the participants

$P D$ Parkinson's Disease, $P D_{T}$ PD patients subgroup with moderate/severe tremor at onset, $P D_{W T}$ PD patients subgroup without tremor at

\begin{tabular}{|c|c|c|c|c|c|c|c|}
\hline & \multicolumn{4}{|l|}{ Baseline } & \multicolumn{3}{|c|}{17 months follow-up } \\
\hline & $\begin{array}{l}\text { Co } \\
(n=13)\end{array}$ & $\begin{array}{l}\mathrm{PD} \\
(n=32)\end{array}$ & $\begin{array}{l}\mathrm{PD}_{\mathrm{T}} \\
(n=8)\end{array}$ & $\begin{array}{l}\mathrm{PD}_{\mathrm{WT}} \\
(n=12)\end{array}$ & $\begin{array}{l}\mathrm{PD} \\
(n=26)\end{array}$ & $\begin{array}{l}\mathrm{PD}_{\mathrm{T}} \\
(n=6)\end{array}$ & $\begin{array}{l}\mathrm{PD}_{\mathrm{wT}} \\
(n=11)\end{array}$ \\
\hline Sex (male) & 8 & 22 & 5 & 5 & 17 & 4 & 5 \\
\hline Age (years, mean $\pm \mathrm{SD}$ ) & $53 \pm 8$ & $54 \pm 10$ & $55 \pm 9$ & $56 \pm 10$ & $56 \pm 9$ & $54 \pm 9$ & $58 \pm 7$ \\
\hline $\begin{array}{l}\text { Disease duration } \\
\quad \text { (years, mean } \pm \mathrm{SD})\end{array}$ & $\S \S$ & $2 \pm 1$ & $2 \pm 1$ & $2 \pm 1$ & $4 \pm 1$ & $4 \pm 1$ & $4 \pm 1$ \\
\hline UPDRS motor score & $\S \S$ & $18 \pm 7$ & $16 \pm 6$ & $19 \pm 8$ & $\S \S$ & $\S \S$ & $\S \S$ \\
\hline UPDRS tremor score (item 20) & $\S \S$ & $1 \pm 1$ & $3 \pm 1$ & 0 & $\S \S$ & $\S \S$ & $\S \S$ \\
\hline $\begin{array}{l}\text { UPDRS bradykinesia/rigidity score } \\
\qquad \begin{array}{l}\text { items: } 18+19+22+27+ \\
28+29+30+31)\end{array}\end{array}$ & $\S \S$ & $13 \pm 6$ & $9 \pm 6$ & $13 \pm 6$ & $\S \S$ & $\S \S$ & $\S \S$ \\
\hline BDI score & $\S \S$ & $8 \pm 6$ & $7 \pm 7$ & $8 \pm 6$ & $\S \S$ & $\S \S$ & $\S \S$ \\
\hline
\end{tabular}
onset, $S D$ standard deviation $\S \S$ data not available 
Difference in mean $\left[{ }^{123} \mathrm{I}\right] \beta$-CIT binding ratio between the various groups was expressed as a percentage and calculated as follows:

$[($ GroupX SNS - GroupY SNS $)-$ GroupX SNS $] \times 100 \%$.

The investigator performing ROI analysis was blind to the subjects' diagnosis as well as demographics.

\section{Statistical analysis}

Statistical analysis was performed using the SPSS 13.0 software package. An independent sample $t$ test with equal variances not assumed was used to investigate the variation in mean $\left[{ }^{123} \mathrm{I}\right] \beta$-CIT binding values between PD patients and healthy control subjects. We compared $\left[{ }^{123} \mathrm{I}\right] \beta$-CIT binding values between $\mathrm{PD}_{\mathrm{T}}$ and $\mathrm{PD}_{\mathrm{WT}}$ cohorts using oneway Analysis of Variance (ANOVA). A paired simple two tailed $t$ test was used to examine the change between the same group imaging results analyzed at baseline and at follow-up (i.e., $\mathrm{PD}$ patients, $\mathrm{PD}_{\mathrm{T}}$ and $\mathrm{PD}_{\mathrm{WT}}$ subgroup). The Kolmogrov-Smirnov and the Levene's test were applied to screen for normality and equal variance, respectively. Additionally, to increase statistical power, we attempted to normalize PD putamen and $\mathrm{PD}_{\mathrm{WT}}$ striatum binding values with an algorithmic $\left[\log _{10}(x+1)\right]$ and an inverse $(1 / x)$ transformation, respectively. Conversely, putamen and thalamic binding values of the $\mathrm{PD}_{\mathrm{T}}$ cohort at follow-up could not be normalized using these transformations, thus were compared to the respective values of the $\mathrm{PD}_{\mathrm{T}}$ cohort at baseline using The Mann-Whitney test. The latter was also used to compare putamen and thalamic binding values of the $\mathrm{PD}_{\mathrm{T}}$ and $\mathrm{PD}_{\mathrm{WT}}$ subgroup at follow-up.

Pearson bivariate correlation was used to correlate BDI scores with thalamic $\left[{ }^{123} \mathrm{I}\right] \beta$-CIT binding values. BDI scores were normalized using the formula: $\log _{10}(x+1)$. One-way ANOVA was applied to examine variations in mean BDI score between $\mathrm{PD}_{\mathrm{T}}$ and $\mathrm{PD}_{\mathrm{WT}}$ subgroups.

Differences between groups were considered significant at a level of $p \leq 0.05$.

\section{Results}

There was no difference with regard to demographic features (age and disease duration) between PD patients and healthy controls and between the $\mathrm{PD}_{\mathrm{T}}$ and $\mathrm{PD}_{\mathrm{WT}}$ cohorts (Table 1).

PD patients had an average of $61 \%$ lower putaminal SNS $\left[{ }^{123} \mathrm{I}\right] \beta$-CIT binding ratios than healthy controls. In addition, average caudate nucleus and whole striatum SNS binding ratios were also significantly lower in PD patients compared to healthy controls (Table 2). We found a significant reduction of $22 \%$ in mean thalamic SNS $\left[{ }^{123} \mathrm{I}\right] \beta$-CIT binding ratio in PD patients versus healthy controls (Table 2). Interestingly, mean SNS thalamic binding ratio was significantly lower in the $\mathrm{PD}_{\mathrm{T}}$ as compared to the $\mathrm{PD}_{\mathrm{WT}}$ cohort by $19 \%$ (Table 2, Fig. 2). Conversely, there was no significant difference in whole striatum, putamen and caudate nucleus average SNS binding ratios between $\mathrm{PD}_{\mathrm{T}}$ and $\mathrm{PD}_{\mathrm{WT}}$ (Table 2).

Average putaminal SNS $\left[{ }^{123} \mathrm{I}\right] \beta$-CIT ratio in repeated scans showed a significant decline of $17 \%$ from the baseline (Table 3). Notably, we found that thalamic SNS $\left[{ }^{123} \mathrm{I}\right] \beta$-CIT binding ratio was significantly further decreased at follow-up as compared to the PD baseline measurement by $29 \%$ (Table 3; Fig. 1). Note that there was no significant difference in thalamic SNS binding ratios between $\mathrm{PD}_{\mathrm{T}}$ and $\mathrm{PD}_{\mathrm{WT}}$ subgroups at the time of the second $\left[{ }^{123} \mathrm{I}\right] \beta$-CIT SPECT (Fig. 2). Whereas, there was no significant difference in putaminal and thalamic radiotracer binding between $\mathrm{PD}_{\mathrm{T}}$ cohort at baseline, and at follow-up putaminal and thalamic $\left[{ }^{123} \mathrm{I}\right] \beta$-CIT binding was significantly decreased in the $\mathrm{PD}_{\mathrm{WT}}$ subgroup at the time of the second as compared to the first scan (19 and 39\%, respectively) (Table 3; Fig. 2).

Thalamic SNS binding ratios did not correlate with BDI scores and there was no difference in BDI score between $\mathrm{PD}_{\mathrm{T}}$ and $\mathrm{PD}_{\mathrm{WT}}$ (Table 1).

\section{Discussion}

We found that mean $\left[{ }^{123} \mathrm{I}\right] \beta$-CIT SPECT putaminal binding was reduced in all early PD patients at baseline as well as at follow-up. This is in agreement with findings from previous studies (Booij et al. 1997a; Tissingh et al. 1998) and with the clinical PD diagnosis. Moreover, average thalamic 5-HTT binding was decreased in early drug-naïve PD patients compared to controls and declined as the disease proceeded. The $\mathrm{PD}_{\mathrm{T}}$ cohort displayed a lower 5-HTT thalamic binding when compared to the $\mathrm{PD}_{\mathrm{WT}}$ cohort at baseline, while no difference could be detected during follow-up. Finally, in the $\mathrm{PD}_{\mathrm{WT}}$ subgroup a further decline in both putaminal and thalamic binding was detected at follow-up, which was not true for the $\mathrm{PD}_{\mathrm{T}}$ subgroup.

To our knowledge, this is the first longitudinal study to investigate 5-HTT loss in PD. Van Dyck et al. (2000) reported a mean $4.2 \%$ per decade age-related decline of 5HTT in the diencephalon of healthy humans by means of $\left[{ }^{123} \mathrm{I}\right] \beta$-CIT SPECT. However, this decay rate is much lower that the one we presently reported in PD patients (29\% over 17 months). Therefore, whereas 5-HTT loss may occur with age on a physiological basis, consistent with our results its decay appears more severe in PD patients. These data confirm the first two hypotheses we stated, according to our results 5-HTT is decreased in PD 
Table 2 Mean specific to non-specific $\left[{ }^{123} \mathrm{I}\right] \beta$-CIT binding ratios (mean $\pm \mathrm{SD}$ ) assessed at baseline

\begin{tabular}{|c|c|c|c|c|}
\hline \multirow[t]{2}{*}{ Region of interest } & \multicolumn{4}{|l|}{ Baseline } \\
\hline & Controls $(n=13)$ & PD patients $(n=32)$ & $\mathrm{PD}_{\mathrm{T}}(n=8)$ & $\operatorname{PD}_{\mathrm{WT}}(n=12)$ \\
\hline Striatum, whole & $8.65 \pm 2.61$ & $4.39 \pm 1.10^{*}$ & $4.38 \pm 0.95$ & $4.21 \pm 1.45$ \\
\hline Caudate, whole & $9.43 \pm 2.55$ & $6.34 \pm 1.55^{*}$ & $5.60 \pm 0.98$ & $6.93 \pm 1.93$ \\
\hline Putamen, whole & $7.72 \pm 2.65$ & $3.02 \pm 0.85^{*}$ & $3.08 \pm 0.79$ & $2.87 \pm 1.10$ \\
\hline Thalamus, whole & $1.98 \pm 0.56$ & $1.55 \pm 0.34 *$ & $1.37 \pm 0.37$ & $1.70 \pm 0.33^{*}$ \\
\hline
\end{tabular}

* Significant difference between controls and PD patients $(* p \leq 0.02)$ and between $\mathrm{PD}_{\mathrm{T}}$ and $\mathrm{PD}_{\mathrm{WT}}$ patients $(p=0.05)$

$P D$ Parkinson's disease, $P D_{T}$ PD patients subgroup with moderate/severe tremor at onset, $P D_{W T}$ PD patients subgroup without tremor at onset, $S D$ standard deviation

Table 3 Mean specific to non-specific $\left[{ }^{123} \mathrm{I}\right] \beta$-CIT binding ratio (mean \pm SD) at baseline and at follow-up (17 \pm 9 months later)

\begin{tabular}{lllllll}
\hline $\begin{array}{l}\text { Region of } \\
\text { interest }\end{array}$ & $\begin{array}{l}\text { Baseline PD } \\
(n=26)\end{array}$ & $\begin{array}{l}\text { Follow-up PD } \\
(n=26)\end{array}$ & $\begin{array}{l}\text { Baseline } \mathrm{PD}_{\mathrm{T}} \\
(n=6)\end{array}$ & $\begin{array}{l}\text { Follow-up } \mathrm{PD}_{\mathrm{T}} \\
(n=6)\end{array}$ & $\begin{array}{l}\text { Baseline PD }_{\mathrm{WT}} \\
(n=12)\end{array}$ & $\begin{array}{l}\text { Follow-up PD } \\
(n=11)\end{array}$ \\
\hline Striatum, whole & $4.17 \pm 0.95$ & $3.86 \pm 0.75$ & $4.16 \pm 0.98$ & $3.79 \pm 0.42$ & $3.91 \pm 1.1$ & $3.64 \pm 0.73$ \\
Caudate, whole & $6.13 \pm 1.47$ & $5.60 \pm 1.36$ & $5.88 \pm 1.36$ & $5.65 \pm 0.68$ & $5.76 \pm 1.58$ & $5.52 \pm 1.16$ \\
Putamen, whole & $2.84 \pm 0.71$ & $2.36 \pm 0.51^{*}$ & $2.83 \pm 0.52$ & $2.37 \pm 0.29$ & $2.74 \pm 0.93$ & $2.22 \pm 0.40^{*}$ \\
Thalamus, whole & $1.50 \pm 0.35$ & $1.07 \pm 0.39^{*}$ & $1.26 \pm 0.34$ & $1.16 \pm 0.29$ & $1.65 \pm 0.31$ & $1.00 \pm 0.45^{*}$ \\
\hline
\end{tabular}

* Significant difference between PD patients at baseline and at follow-up $(p<0.01)$ and between $\mathrm{PD}_{\mathrm{WT}}$ subgroup at baseline and at follow-up $(p<0.05)$

$P D$ Parkinson's disease, $P D_{T}$ PD patients subgroup with moderate/severe tremor at onset, $P D_{W T}$ PD patients subgroup without tremor at onset, $S D$ standard deviation

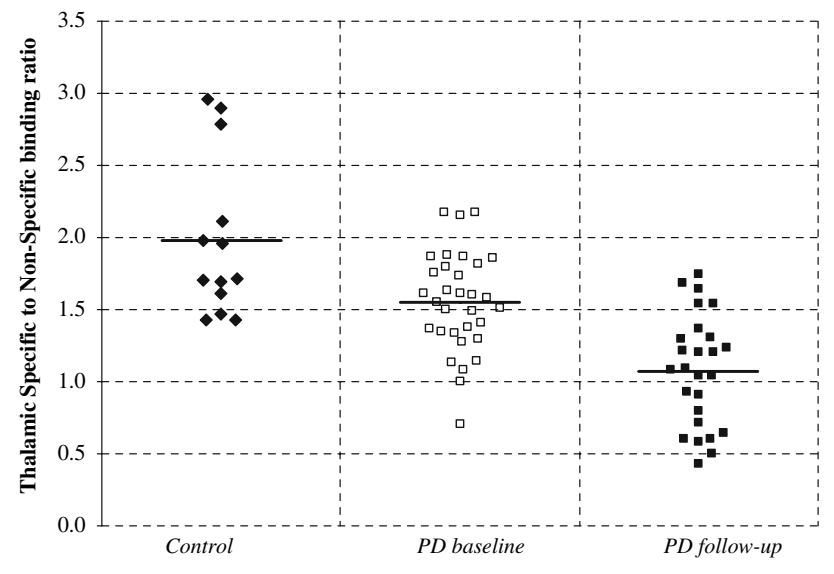

Fig. 1 Scatterplot showing the rate of change in thalamic specific to non-specific $\left[{ }^{123} \mathrm{I}\right] \beta$-CIT binding ratio in healthy controls and in PD patients at baseline and at follow-up. At the time of the first imaging series, mean thalamic $\left[{ }^{123} \mathrm{I}\right] \beta$-CIT binding ratio was significantly lower in PD patients as compared to controls $(p=0.02)$. Moreover, mean thalamic ratio obtained in PD patients was significantly lower at the follow-up as compared to the baseline $(p<0.01)$. Second scan data were obtained an average of 17 month later. PD baseline and PD follow-up indicate PD patients at baseline and at the follow-up, respectively

and further declines along with the disease. Noteworthy, it has been argued that $\left[{ }^{123} \mathrm{I}\right] \beta$-CIT radiotracer in the thalamus may bind to monoaminergic transporters other than 5-HTT. In particular, in a monkey PET study (Farde et al.
1994) citalopram as well as desipramine, a norepinephrine transporter (NET) blocker, was able to displace thalamic $\left[{ }^{123} \mathrm{I}\right] \beta$-CIT binding by 50 and $40 \%$, respectively. Conversely, Laruelle et al. (1993) demonstrated that the selective NET inhibitor maprotiline failed to affect $\left[{ }^{123} \mathrm{I}\right] \beta$ CIT binding in monkey diencephalon. Additionally, concerning SPECT studies in humans, De Win et al. (2005) validated $\left[{ }^{123} \mathrm{I}\right] \beta$-CIT to assess in vivo 5 -HTT in the thalamic area. Importantly, in this study, a double-blind, placebo-controlled, crossover design with citalopram (the most selective 5-HTT blocker) was performed. Moreover, it has been demonstrated that citalopram blocks approximately $50 \%$ of thalamic $\left[{ }^{123} \mathrm{I}\right] \beta$-CIT binding in depressed patients (Pirker et al. 1995). Interestingly, in a recent study (Shang et al. 2007), venlafaxine (a 5-HTT and NET inhibitor) proved to decrease $\left[{ }^{123} \mathrm{I}\right] \beta$-CIT SPECT binding by $54 \%$, an outcome similar to the one obtained by Pirker et al. (1995). Therefore, it may be argued that in vivo only a small part of the $\left[{ }^{123} \mathrm{I}\right] \beta$-CIT binding to human thalamus is due to NET binding. Finally, it must be taken into account that in the human brain 5-HTT is much higher than NET thalamic concentration (Tong et al. 2007), while the affinity of $\left[{ }^{123} \mathrm{I}\right] \beta$-CIT (or RTI-55) for NET is lower than for 5-HTT (Scheffel et al. 1997). To summarize, although we cannot exclude that in vivo $\left[{ }^{123} \mathrm{I}\right] \beta$-CIT binding in the human thalamus, may be partly due to NET binding; the largest part likely represents 5-HTT binding. Nonetheless, 


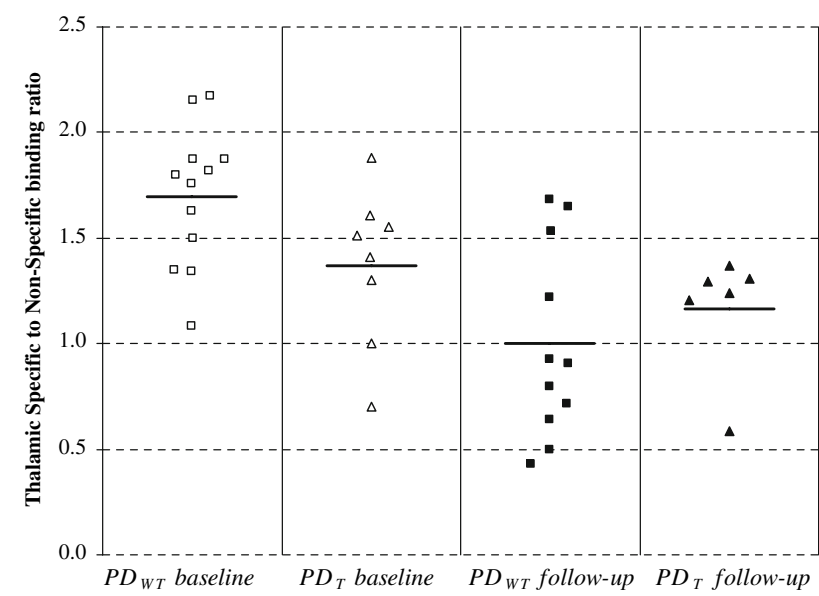

Fig. 2 Scatterplot showing the rate of change in thalamic specific to non-specific $\left[{ }^{123} \mathrm{I}\right] \beta$-CIT binding ratio in the $\mathrm{PD}_{\mathrm{WT}}$ as compared to the $\mathrm{PD}_{\mathrm{T}}$ subgroup over time. Mean thalamic $\left[{ }^{123} \mathrm{I}\right] \beta$-CIT binding ratio was significantly lower in the $\mathrm{PD}_{\mathrm{T}}$ versus the $\mathrm{PD}_{\mathrm{WT}}$ subgroup at baseline $(p=0.05)$. No difference in mean thalamic ratio between the $\mathrm{PD}_{\mathrm{T}}$ and the $\mathrm{PD}_{\mathrm{WT}}$ subset was detected at the time of the second imaging series. Moreover, mean thalamic ratio in the $\mathrm{PD}_{\mathrm{WT}}$ subgroup was significantly lower at follow-up than at baseline $(p<0.01)$. Conversely no difference was found in the $\mathrm{PD}_{\mathrm{T}}$ subset. Second scan data $\mathrm{PD}_{\mathrm{T}}$ were obtained in an average of 17 month later. $\mathrm{PD}_{\mathrm{T}}$ and $\mathrm{PD}_{\mathrm{WT}}$ indicate $\mathrm{PD}$ patients subgroups with moderate/severe tremor and without tremor at onset, respectively

further studies with selective radiotracers for 5-HTT are needed to reproduce our findings. In this context, two previous PET studies with selective 5-HTT tracers found no significant thalamic 5-HTT decrease in PD patients when compared to controls (Guttman et al. 2007; Kerenyi et al. 2003). In particular, Kerenyi et al. describe a trend for lower thalamic 5-HTT binding with a decrease of approximately $25 \%$, a range loss similar to the one we presently report $(22 \%)$. Importantly, the small number of participants investigated in the PET studies mentioned above ( 9 and 13, respectively) may have played a role for a non-significant thalamic decreased binding outcome. This may be relevant to the present study where a thalamic 5HTT decline over time was demonstrated in a larger cohort of 26 PD patients.

At baseline, we found lower thalamic 5-HTT density in PD patients with mild to severe tremor compared to patients without tremor. The two cohorts $\left(\mathrm{PD}_{\mathrm{T}}\right.$ and $\left.\mathrm{PD}_{\mathrm{WT}}\right)$ differed in terms of UPDRS tremor scores but were comparable in terms of rigidity and bradykinesia. In fact, $\mathrm{PD}_{\mathrm{T}}$ had a UPDRS resting tremor score $\geq 2$ in at least one limb, whereas, the $\mathrm{PD}_{\mathrm{WT}}$ presented no tremor at all. Resting tremor was the only one out of the cardinal motor features that clinically characterize PD (tremor, bradykinesia, rigidity and postural instability) to differentiate the two patient subsets. Moreover, the absence of significant differences in striatal DAT binding between the two subgroups confirms the assumption we made based on previous studies: bradykinesia and rigidity but not tremor correlates with striatal DAT binding (Spiegel et al. 2006). These data suggest that 5-HT may play a role in the etiology of resting tremor in early PD stages. In this context, Haapaniemi et al. reported a lower thalamic $\left[{ }^{123} \mathrm{I}\right] \beta$-CIT binding in PD compared to controls, although, in contrast with our results, no correlation to tremor scores was detected (Haapaniemi et al. 2001). Difference in results may be due to measuring methods. We obtained data $24 \mathrm{~h}$ post-injection, whereas they acquired scans at $4 \mathrm{~h}$ postinjection. Although there is still considerable debate as to the best timing to acquire SPECT images (Brucke et al. 1993; Laruelle et al. 1994b), scans obtained between 20 and $24 \mathrm{~h}$ showed to be closer to a state of transient equilibrium (Pirker et al. 2000).

Recently, Doder et al. (2003) reported a reduction of in vivo raphe $5-\mathrm{HT}_{1 \mathrm{~A}}$ binding in $\mathrm{PD}$ patients and an association with the severity of UPDRS tremor scores using ${ }^{11} \mathrm{C}$ WAY 100635 PET. The authors suggested that this reduction expresses loss of 5-HT cell bodies, possibly due to Lewy body degeneration. Our present finding indicating thalamic $\left[{ }^{123} \mathrm{I}\right] \beta$-CIT binding decline is in agreement with this hypothesis, since the 5-HTT is located exclusively on the 5-HT neuronal membrane. Alternatively, 5-HT and dopaminergic activity may decline in parallel in the striatum and in the midbrain of parkinsonian patients, particularly in patients with tremor onset. Reduced serotonergic function would result in less inhibition and in turn facilitate striatal dopamine release (De et al. 2004; Di, V et al. 2002; Jacobs et al. 1993). We investigated PD patients at onset, and did not investigate radiotracer binding within raphe nuclei; whereas Doder et al. examined participants at an advanced stage and did not analyze the thalamic area. Note that unlike their study, we chose not to correlate thalamic binding to UPDRS total tremor scores. In fact, patients we enrolled were at an early stage and thus presented a very low total tremor score (mean items 20 total score $\pm \mathrm{SD}=1 \pm 1$ ). Due to such a low variance in total tremor score, a correlation between these values and SNS thalamic binding could not have been evaluated adequately. Also note that both studies did not take into account 5-HTT levels in striatal and cortical regions, which express low to moderate 5-HTT concentrations. According to Braak et al. (2003) midbrain stem is the first component of the somato-motor and emotional motor system to be affected, whereas, the degeneration of cells in the substantia nigra, thalamic nuclei and neocortical areas follows. In the light of this evidence, a comparison between 5-HTT availability among brain areas presenting 5-HTT in subsequent PD stages by means of selective 5-HTT tracers is warranted to better assess the role of 5-HT in PD. In fact, although in PD alterations of striatal and cortical 5-HTT may be associated with tremor, in the present study we 
were not able to assess striatal 5-HTT binding, as $\left[{ }^{123} \mathrm{I}\right] \beta$ CIT binds predominantly to DAT in the striatum (Laruelle et al. 1993). Additionally, although we provided some evidence that $\left[{ }^{123} \mathrm{I}\right] \beta$-CIT SPECT may be used to measure 5-HTT in 5-HTT-low cortical areas, these measurements must be interpreted with caution (De Win et al. 2005).

Unlike baseline imaging, the repeated scans showed no statistical difference in thalamic 5-HTT binding between the $\mathrm{PD}_{\mathrm{WT}}$ and $\mathrm{PD}_{\mathrm{T}}$ group. Furthermore, the $\mathrm{PD}_{\mathrm{WT}}$ subgroup revealed a faster 5-HTT thalamic decline as compared to the $\mathrm{PD}_{\mathrm{T}}$ group. It has been demonstrated that $\mathrm{PD}$ patients, who manifest symptoms at a relatively $\left[{ }^{123} \mathrm{I}\right] \beta$ CIT high density, progress substantially faster than those who manifest symptoms at a lower transporter density (Seibyl et al. 1999). While we do not have an explanation for this phenomenon, a progressive loss of surviving neurons could be postulated. Both Lewy body degeneration and reduced 5-HTT inhibiting activity over the striatum might have a major effect in those patients still presenting with a high transporter density. Additionally, we were not able to assess whether tremor had eventually revealed in the $\mathrm{PD}_{\mathrm{WT}}$ subgroup at the time of the second scan, as patients were under dopaminergic treatment. Indeed the lack of follow-up UPDRS clinical examinations represents a limitation of our study.

5-HT neurotransmission is impaired in PD, but its causal relationship with tremor remains controversial and it is unclear what the clinical relevance of a $22 \%$ thalamic 5HTT loss is. Due to the design of the present study, our findings do not allow a definitive answer on PD tremor but certainly supports the role of 5-HTT function.

As of yet, $\left[{ }^{123} \mathrm{I}\right] \beta$-CIT SPECT imaging correlating 5HTT binding decline to depressive symptoms in PD has revealed inconsistent results. Kim et al. (1999) reported no significant correlation between hypothalamic/midbrain 5HTT in PD and UPDRS-I (depression items). A further study showed no relationship between 5-HTT binding and UPDRS rating of mood in thalamus, but detected a significant correlation in dorsal midbrain (Murai et al. 2001). Finally, Haapianemi and colleagues demonstrated that 5HTT frontal region binding in PD correlates to UPDRS-I (Haapaniemi et al. 2001). In the present study, we found no correlation between BDI scores and thalamic 5-HTT and, even more importantly, there was no difference in BDI between the $\mathrm{PD}_{\mathrm{T}}$ and $\mathrm{PD}_{\mathrm{WT}}$ subgroups suggesting no contribution of depressive symptoms to these findings. Whereas, we used BDI, a reliable self-assessment scale to assess depression in PD (Visser et al. 2006), other studies used UPDRS rating for mood, which is a less specific screening tool. We did not assess BDI at the follow-up, therefore depressive symptoms may not have been revealed until a more advanced stage, along with thalamic 5-HTT decline.
In conclusion, in this study we show loss of thalamic 5HTT binding in PD and its progressive loss over an average of 17 months. At baseline, a decreased thalamic 5-HTT density in patients presenting tremor at onset was found, while no correlation could be detected between thalamic $\left[{ }^{123} \mathrm{I}\right] \beta$-CIT binding ratios and BDI scores. In this context, further studies with selective 5-HTT tracers are needed to reproduce our findings in early PD. Additionally, new research is warranted to gain a better insight into the causal relation that links 5-HT dysfunction and tremor and depression in PD. Finally, pharmacological challenges with serotonergic agents may be performed to test their potential capacity in counteracting PD tremor.

Open Access This article is distributed under the terms of the Creative Commons Attribution Noncommercial License which permits any noncommercial use, distribution, and reproduction in any medium, provided the original author(s) and source are credited.

\section{References}

Antonini A, Tesei S, Zecchinelli A, Barone P, De Gaspari D, Canesi M, Sacilotto G, Meucci N, Mariani C, Pezzoli G (2006) Randomized study of sertraline and low-dose amitriptyline in patients with Parkinson's disease and depression: effect on quality of life. Mov Disord 21:1119-1122

Barone P, Scarzella L, Marconi R, Antonini A, Morgante L, Bracco F, Zappia M, Musch B (2006) Pramipexole versus sertraline in the treatment of depression in Parkinson's disease: a national multicenter parallel-group randomized study. J Neurol 253:601-607

Benabid AL, Pollak P, Louveau A, Henry S, de Rougemont J (1987) Combined (thalamotomy and stimulation) stereotactic surgery of the VIM thalamic nucleus for bilateral Parkinson disease. Appl Neurophysiol 50:344-346

Birkmayer W, Birkmayer JD (1987) Dopamine action and disorders of neurotransmitter balance. Gerontology 33:168-171

Birkmayer W, Knoll J, Riederer P, Youdim MB, Hars V, Marton J (1985) Increased life expectancy resulting from addition of $\mathrm{L}-$ deprenyl to Madopar treatment in Parkinson's disease: a longterm study. J Neural Transm 64:113-127

Boja JW, Cadet JL, Kopajtic TA, Lever J, Seltzman HH, Wyrick CD, Lewin AH, Abraham P, Carroll FI (1995) Selective labeling of the dopamine transporter by the high affinity ligand 3 beta-(4$\left[{ }^{125}\right.$ I]iodophenyl)tropane-2 beta-carboxylic acid isopropyl ester. Mol Pharmacol 47:779-786

Booij J, Tissingh G, Boer GJ, Speelman JD, Stoof JC, Janssen AG, Wolters EC, van Royen EA (1997a) [ ${ }^{123}$ I]FP-CIT SPECT shows a pronounced decline of striatal dopamine transporter labelling in early and advanced Parkinson's disease. J Neurol Neurosurg Psychiatry 62:133-140

Booij J, Tissingh G, Winogrodzka A, Boer GJ, Stoof JC, Wolters EC, van Royen EA (1997b) Practical benefit of $\left[{ }^{123}\right.$ I]FP-CIT SPET in the demonstration of the dopaminergic deficit in Parkinson's disease. Eur J Nucl Med 24:68-71

Bowman WC, Osuide G (1968) Interaction between the effects of tremorine and harmine and of other drugs in chicks. Eur $\mathbf{J}$ Pharmacol 3:106-111

Braak H, Del Tredici K, Rub U, de Vos RA, Jansen Steur EN, Braak E (2003) Staging of brain pathology related to sporadic Parkinson's disease. Neurobiol Aging 24:197-211 
Brucke T, Kornhuber J, Angelberger P, Asenbaum S, Frassine H, Podreka I (1993) SPECT imaging of dopamine and serotonin transporters with $\left[{ }^{123} \mathrm{I}\right]$ beta-CIT. Binding kinetics in the human brain. J Neural Transm Gen Sect 94:137-146

Chaudhuri A (2006) Guillain-Barre syndrome. Lancet 367:472-473

de Rijk MC, Rocca WA, Anderson DW, Melcon MO, Breteler MM, Maraganore DM (1997) A population perspective on diagnostic criteria for Parkinson's disease. Neurology 48:1277-1281

De Win MM, Habraken JB, Reneman L, Van den Brink W, Den Heeten GJ, Booij J (2005) Validation of $\left[\left({ }^{123}\right)\right.$ I] beta-CIT SPECT to assess serotonin transporters in vivo in humans: a doubleblind, placebo-controlled, crossover study with the selective serotonin reuptake inhibitor citalopram. Neuropsychopharmacology 30:996-1005

De Deurwaerdere P, Navailles S, Berg KA, Clarke WP, Spampinato U (2004) Constitutive activity of the serotonin2C receptor inhibits in vivo dopamine release in the rat striatum and nucleus accumbens. J Neurosci 24:3235-3241

DeLong MR (1978) Possible involvement of central pacemakers in clinical disorders of movement. Fed Proc 37:2171-2175

Di Matteo V, Cacchio M, Di Giulio C, Esposito E (2002) Role of serotonin(2C) receptors in the control of brain dopaminergic function. Pharmacol Biochem Behav 71:727-734

Doder M, Rabiner EA, Turjanski N, Lees AJ, Brooks DJ (2003) Tremor in Parkinson's disease and serotonergic dysfunction: an 11C-WAY 100635 PET study. Neurology 60:601-605

Farde L, Halldin C, Muller L, Suhara T, Karlsson P, Hall H (1994) PET study of [11C]beta-CIT binding to monoamine transporters in the monkey and human brain. Synapse 16:93-103

Fink KB, Gothert M (2007) 5-HT Receptor Regulation of Neurotransmitter Release. Pharmacol Rev

Forno LS (1996) Neuropathology of Parkinson's disease. J Neuropathol Exp Neurol 55:259-272

Guttman M, Boileau I, Warsh J, Saint-Cyr JA, Ginovart N, McCluskey T, Houle S, Wilson A, Mundo E, Rusjan P, Meyer J, Kish SJ (2007) Brain serotonin transporter binding in nondepressed patients with Parkinson's disease. Eur J Neurol 14:523-528

Haapaniemi TH, Ahonen A, Torniainen P, Sotaniemi KA, Myllyla VV (2001) [ ${ }^{123}$ I]beta-CIT SPECT demonstrates decreased brain dopamine and serotonin transporter levels in untreated parkinsonian patients. Mov Disord 16:124-130

Headley PM, Lodge D, Duggan AW (1976) Drug-induced rhythmical activity in the inferior olivary complex of the rat. Brain Res 101:461-478

Henderson JM, Carpenter K, Cartwright H, Halliday GM (2000a) Degeneration of the centre median-parafascicular complex in Parkinson's disease. Ann Neurol 47:345-352

Henderson JM, Carpenter K, Cartwright H, Halliday GM (2000b) Loss of thalamic intralaminar nuclei in progressive supranuclear palsy and Parkinson's disease: clinical and therapeutic implications. Brain 123(Pt 7):1410-1421

Hirsch EC, Orieux G, Muriel MP, Francois C, Feger J (2003) Nondopaminergic neurons in Parkinson's disease. Adv Neurol 91:29-37

Hughes AJ, Ben-Shlomo Y, Daniel SE, Lees AJ (1992) What features improve the accuracy of clinical diagnosis in Parkinson's disease: a clinicopathologic study. Neurology 42:1142-1146

Innis R, Baldwin R, Sybirska E, Zea Y, Laruelle M, al-Tikriti M, Charney D, Zoghbi S, Smith E, Wisniewski G (1991) Single photon emission computed tomography imaging of monoamine reuptake sites in primate brain with $\left[{ }^{123} \mathrm{I}\right] \mathrm{CIT}$. Eur J Pharmacol 200:369-370

Innis RB (1994) Single-photon emission tomography imaging of dopamine terminal innervation: a potential clinical tool in Parkinson's disease. Eur J Nucl Med 21:1-5
Jacobs BL, Fornal CA (1993) 5-HT and motor control: a hypothesis. Trends Neurosci 16:346-352

Jellinger K (1987) Overview of morphological changes in Parkinson's disease. Adv Neurol 45:1-18

Kerenyi L, Ricaurte GA, Schretlen DJ, McCann U, Varga J, Mathews WB, Ravert HT, Dannals RF, Hilton J, Wong DF, Szabo Z (2003) Positron emission tomography of striatal serotonin transporters in Parkinson disease. Arch Neurol 60:1223-1229

Kim SE, Lee WY, Choe YS, Kim JH (1999) SPECT measurement of iodine-123-beta-CIT binding to dopamine and serotonin transporters in Parkinson's disease: correlation with symptom severity. Neurol Res 21:255-261

Koller WC, Hubble JP (1990) Levodopa therapy in Parkinson's disease. Neurology 40:(7)

Kostic VS, Djuricic BM, Covickovic-Sternic N, Bumbasirevic L, Nikolic M, Mrsulja BB (1987) Depression and Parkinson's disease: possible role of serotonergic mechanisms. J Neurol 234:94-96

Kuhn W, Muller T, Gerlach M, Sofic E, Fuchs G, Heye N, Prautsch R, Przuntek H (1996) Depression in Parkinson's disease: biogenic amines in CSF of "de novo" patients. J Neural Transm 103:1441-1445

Lamarre Y, Joffroy AJ, Dumont M, De Montigny C, Grou F, Lund JP (1975) Central mechanisms of tremor in some feline and primate models. Can J Neurol Sci 2:227-233

Laruelle M, Baldwin RM, Malison RT, Zea-Ponce Y, Zoghbi SS, alTikriti MS, Sybirska EH, Zimmermann RC, Wisniewski G, Neumeyer JL, (1993) SPECT imaging of dopamine and serotonin transporters with $\left[{ }^{123} \mathrm{I}\right]$ beta-CIT: pharmacological characterization of brain uptake in nonhuman primates. Synapse 13:295-309

Laruelle M, Baldwin RM, Innis RB (1994a) SPECT imaging of dopamine and serotonin transporters in nonhuman primate brain. NIDA Res Monogr 138:131-159

Laruelle M, Wallace E, Seibyl JP, Baldwin RM, Zea-Ponce Y, Zoghbi SS, Neumeyer JL, Charney DS, Hoffer PB, Innis RB (1994b) Graphical, kinetic, and equilibrium analyses of in vivo $\left[{ }^{123} \mathrm{I}\right]$ beta-CIT binding to dopamine transporters in healthy human subjects. J Cereb Blood Flow Metab 14:982-994

Limousin P, Speelman JD, Gielen F, Janssens M (1999) Multicentre European study of thalamic stimulation in parkinsonian and essential tremor. J Neurol Neurosurg Psychiatry 66:289-296

Limousin-Dowsey P, Pollak P, Van Blercom N, Krack P, Benazzouz A, Benabid A (1999) Thalamic subthalamic nucleus and internal pallidum stimulation in Parkinson's disease. J Neurol 246(Suppl 2):II42-II45

Mossner R, Henneberg A, Schmitt A, Syagailo YV, Grassle M, Hennig T, Simantov R, Gerlach M, Riederer P, Lesch KP (2001) Allelic variation of serotonin transporter expression is associated with depression in Parkinson's disease. Mol Psychiatry 6:350 352

Murai T, Muller U, Werheid K, Sorger D, Reuter M, Becker T, von Cramon DY, Barthel H (2001) In vivo evidence for differential association of striatal dopamine and midbrain serotonin systems with neuropsychiatric symptoms in Parkinson's disease. J Neuropsychiatry Clin Neurosci 13:222-228

Neumeyer JL, Wang SY, Milius RA, Baldwin RM, Zea-Ponce Y, Hoffer PB, Sybirska E, al-Tikriti M, Charney DS, Malison RT, (1991) $\left[{ }^{123} \mathrm{I}\right]-2$ beta-carbomethoxy-3 beta-(4-iodophenyl)tropane: high-affinity SPECT radiotracer of monoamine reuptake sites in brain. J Med Chem 34:3144-3146

Pirker W, Asenbaum S, Kasper S, Walter H, Angelberger P, Koch G, Pozzera A, Deecke L, Podreka I, Brucke T (1995) beta-CIT SPECT demonstrates blockade of 5HT-uptake sites by citalopram in the human brain in vivo. J Neural Transm Gen Sect 100:247-256 
Pirker W, Asenbaum S, Hauk M, Kandlhofer S, Tauscher J, Willeit M, Neumeister A, Praschak-Rieder N, Angelberger P, Brucke T (2000) Imaging serotonin and dopamine transporters with ${ }^{123}$ I-beta-CIT SPECT: binding kinetics and effects of normal aging. J Nucl Med 41:36-44

Scatton B, Javoy-Agid F, Rouquier L, Dubois B, Agid Y (1983) Reduction of cortical dopamine, noradrenaline, serotonin and their metabolites in Parkinson's disease. Brain Res 275:321-328

Scheffel U, Lever JR, Abraham P, Parham KR, Mathews WB, Kopajtic T, Carroll FI, Kuhar MJ (1997) N-substituted phenyltropanes as in vivo binding ligands for rapid imaging studies of the dopamine transporter. Synapse 25:345-349

Schnitzler A, Timmermann L, Gross J (2006) Physiological and pathological oscillatory networks in the human motor system. J Physiol Paris 99:3-7

Seibyl JP, Innis R, Early ML, et al (1999) Baseline striatal dopamine transporter uptake measured with $\left[{ }^{123} \mathrm{I}\right] \mathrm{a}-\mathrm{CIT}$ SPECT may predict the rate of disease progression in idiopathic Parkinson's disease. J Nucl Med 40:27

Shang Y, Gibbs MA, Marek GJ, Stiger T, Burstein AH, Marek K, Seibyl JP, Rogers JF (2007) Displacement of serotonin and dopamine transporters by venlafaxine extended release capsule at steady state: a $\left[{ }^{123} \mathrm{I}\right] 2$ beta-carbomethoxy-3beta-(4-iodophenyl)-tropane single photon emission computed tomography imaging study. J Clin Psychopharmacol 27:71-75

Spiegel J, Hellwig D, Samnick S, Jost W, Mollers MO, Fassbender K, Kirsch CM, Dillmann U (2006) Striatal FP-CIT uptake differs in the subtypes of early Parkinson's disease. J Neural Transm 114(3):331-335
Timmermann L, Gross J, Dirks M, Volkmann J, Freund HJ, Schnitzler A (2003) The cerebral oscillatory network of parkinsonian resting tremor. Brain 126:199-212

Tissingh G, Bergmans P, Booij J, Winogrodzka A, van Royen EA, Stoof JC, Wolters EC (1998) Drug-naive patients with Parkinson's disease in Hoehn and Yahr stages I and II show a bilateral decrease in striatal dopamine transporters as revealed by $\left[{ }^{123}\right.$ I] beta-CIT SPECT. J Neurol 245:14-20

Tong J, Hornykiewicz O, Furukawa Y, Kish SJ (2007) Marked dissociation between high noradrenaline versus low noradrenaline transporter levels in human nucleus accumbens. J Neurochem 102:1691-1702

van Dyck CH, Malison RT, Seibyl JP, Laruelle M, Klumpp H, Zoghbi SS, Baldwin RM, Innis RB (2000) Age-related decline in central serotonin transporter availability with $\left[\left({ }^{123}\right)\right.$ I] beta-CIT SPECT. Neurobiol Aging 21:497-501

Vermeulen RJ, Wolters EC, Tissingh G, Booij J, Janssen AG, Habraken J, Sokole-Busemann E, Stoof JC, Van Royen EA (1995) Evaluation of $\left[{ }^{123} \mathrm{I}\right]$ beta-CIT binding with SPECT in controls, early and late Parkinson's disease. Nucl Med Biol 22:985-991

Visser M, Leentjens AF, Marinus J, Stiggelbout AM, van Hilten JJ (2006) Reliability and validity of the Beck depression inventory in patients with Parkinson's disease. Mov Disord 21:668-672

Volkmann J, Joliot M, Mogilner A, Ioannides AA, Lado F, Fazzini E, Ribary U, Llinas R (1996) Central motor loop oscillations in parkinsonian resting tremor revealed by magnetoencephalography. Neurology 46:1359-1370

Wilms H, Sievers J, Deuschl G (1999) Animal models of tremor. Mov Disord 14:557-571 